\title{
STUDI KOMPARASI PENGGUNAAN KUNYIT DENGAN IRADIATOR SEBAGAI PENGAWET TAHU DENGAN PENDEKATAN LIFE CYCLE ASSESSMENT
}

\author{
Kartini Megasari $^{1^{*}}$, Rahmawati Yunita ${ }^{1}$, Deni Swantomo ${ }^{1}$ \\ ${ }^{1}$ STTN-BATAN, Kawasan BATAN Yogyakarta, Depok, Sleman, Yogyakarta \\ *Email: kartinimega@batan.go.id
}

\begin{abstract}
ABSTRAK
STUDI KOMPARASI PENGGUNAAN KUNYIT DENGAN IRADIATOR SEBAGAI PENGAWET TAHU DENGAN PENDEKATAN LIFE CYCLE ASSESSMENT. Kontaminasi mikroba pada makanan menimbulkan masalah selama penyimpanan, pengangkutan, dan pemasaran. Dalam mengatasi masalah ini dilakukan pengawetan terhadap makanan, beberapa cara yang dapat dilakukan yaitu pengawetan secara konvensional dan iradiasi. Dalam penerapannya, teknik pengawetan makanan secara konvensional dan iradiasi memiliki kelemahan, sehingga perlu dilakukan studi komparasi menggunakan Life Cycle Assessment (LCA). Salah satu produk pangan yang dapat dilakukan studi LCA adalah tahu. Tujuan penelitian ini untuk menentukan dan membandingkan dampak lingkungan yang ditimbulkan dari penggunaan kunyit dengan iradiator sebagai pengawet tahu dengan pendekatan LCA. LCA dilakukan dengan menggunakan software OpenLCA dengan unit fungsional $41,8335 \mathrm{~kg}$ tahu. Data produksi tahu diperoleh dari produsen tahu yang berbasis di Kotagede Yogyakarta dan PAIR BATAN untuk data pengawetan tahu menggunakan iradiator. Sistem batas LCA mulai dari proses pembuatan tahu sampai menjadi produk jadi (cradle to gate). Dampak lingkungan yang disebabkan dari pengawetan tahu menggunakan kunyit maupun iradiator berupa acidification potential, climate change, eutrophication, freshwater aquatic ecotoxicity, human toxicity, marine aquatic ecotoxicity, photochemical oxidation, dan terrestial ecotoxicity. Kontribusi dampak terhadap lingkungan yang paling dominan terjadi pada pengawetan tahu menggunakan kunyit dan iradiator adalah climate change, dengan kontribusi sebesar 16,67136 dan 14,51325 kg CO2 eq. Berdasarkan studi komparasi yang telah dilakukan, pengawetan tahu menggunakan iradiator lebih ramah lingkungan, sehingga teknologi pengawetan ini dapat dijadikan teknologi alternatif pengawetan makanan.
\end{abstract}

Kata Kunci: cradle to gate, iradiator, life cycle assessment, kunyit, tahu

\begin{abstract}
COMPARATIVE STUDY THE USE OF TURMERIC WITH IRRADIATOR AS A TOFU PRESERVATION WITH LIFE CYCLE ASSESSMENT APPROACH. Microbial contamination of food causes some problems during storage, transport, and marketing. In overcoming this problem can be done food preservation, some ways that can be done are conventional preservation and irradiation. In practice, conventional food preservation techniques and irradiation have disadvantages, so required a comparative study using Life Cycle Assessment (LCA). One of food products that can do by LCA study is tofu. The goal of this study was to evaluate and compare the environmental impact caused by the use of turmeric and irradiator as a food preservative with LCA approach. LCA was performed using OpenLCA software with functional unit $41.8335 \mathrm{~kg}$ tofu. Production data for this study were obtained from tofu factory based in Yogyakarta and PAIR BATAN for tofu preservation using irradiator. The LCA boundary was from cradle to postpacking product (cradle to gate). The environmental impacts caused by tofu preservation using turmeric and irradiator are acidification potential, climate change, eutrophication, freshwater ecotoxicity, human toxicity, marine ecotoxicity, photochemical oxidation, and terrestrial eco-toxicity. The most dominant environmental impacts on tofu preservation using turmeric and irradiator are climate change, with contribution of 16.67136 and $14.51325 \mathrm{~kg} \mathrm{CO} 2$ eq. Based on comparative study, tofu preservation using irradiator more environmentally friendly, so this technology is eligible to be selected as an alternative food preservation technology.
\end{abstract}

Keywords: cradle to gate, irradiator, life cycle assessment, tofu, turmeric 


\section{PENDAHULUAN}

Pengawetan makanan telah menjadi kegelisahan utama manusia selama berabadabad dikarenakan kontaminasi mikroba yang menyebabkan kerugian besar pada makanan selama penyimpanan, pengangkutan dan pemasaran [1].

Ada banyak teknologi pengawetan makanan secara konvensional yang telah dikembangkan untuk membantu mencegah pembusukan makanan, diantaranya pengeringan, pengasapan, pengasinan, pengalengan, pendinginan, pembekuan dan pengawetan menggunakan zat kimia [2].

Salah satu dampak negatif pengawetan makanan secara konvensional dapat merubah aroma dan rasa yang khas dari makanan, mengurangi kandungan gizi makanan, dan juga meninggalkan residu yang berbahaya bagi tubuh manusia. Iradiasi merupakan salah satu alternatif lain dalam pengawetan makanan.

Iradiasi bahan pangan merupakan pengolahan produk makanan menggunakan radiasi pengion yang bertujuan untuk mengontrol bakteri patogen, mengurangi mikroba dan perkembangan kutu, menghambat perkecambahan tanaman, dan memperpanjang umur dari produk yang mudah rusak [2].

Teknologi iradiasi memiliki beberapa keunggulan dibandingkan teknologi konvensional, yaitu tidak merubah warna, bentuk, rasa dan aroma khas, tidak mengurangi kandungan gizi, tidak meninggalkan residu, dan juga ramah lingkungan [3]. Dibalik keunggulan teknologi iradiasi, ada beberapa kekurangan pada teknologi ini, yaitu biayanya mahal, bahan pengemas yang digunakan harus sesuai persyaratan yang berlaku, membutuhkan penanganan zat radioaktif yang digunakan, dan juga membutuhkan penanganan khusus pada saat dekomisioning sumber radioaktif setelah tidak digunakan.

Dalam penerapannya, teknik pengawetan makanan secara konvensional dan iradiasi memiliki kelemahan sehingga perlu dilakukan studi komparasi menggunakan Life Cycle Assessment (LCA). LCA merupakan salah satu teknik pengelolaan lingkungan yang membahas keseluruhan daur hidup produk, mulai dari awal proses produksi, bahan mentah sampai produk menjadi limbah yang digunakan untuk mengetahui jumlah energi, biaya, dan dampak lingkungan yang disebabkan oleh tahapan daur hidup produk [4] [5] [6].

\section{TEORI}

Penakaran daur hidup (Life Cycle Assessment/LCA) adalah suatu metode pengukuran dampak suatu produk tertentu terhadap ekosistem yang dilakukan dengan mengidentifikasikan, mengukur, menganalisis, dan menakar besarnya konsumsi energi, bahan baku, emisi serta faktor-faktor lainnya yang berkaitan dengan produk tersebut sepanjang siklus hidupnya [7]. Dalam penelitian LCA ada empat tahapan analisis, yaitu tahapan pendefinisian tujuan dan ruang lingkup, tahapan analisis persedian, tahapan penilaian dampak, dan tahapan interpretasi [4]. Empat tahapan analisis dalam penelitian LCA disajikan pada Gambar 1.

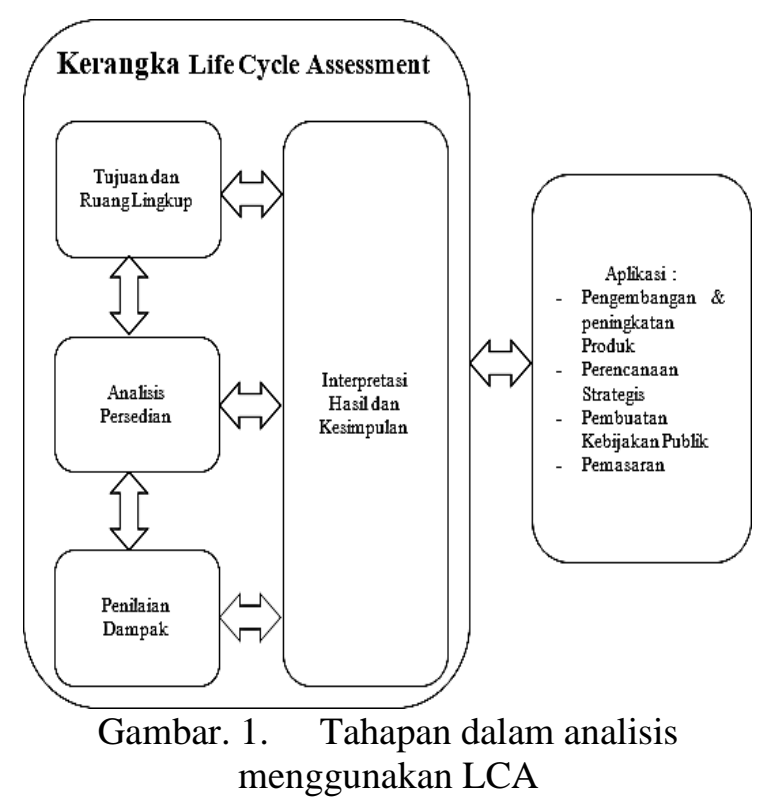

Tujuan dan Ruang Lingkup

Tujuan dari penelitian ini adalah untuk mengevaluasi dampak penggunaan kunyit dan iradiator pada pengawetan tahu dengan menggunakan metode LCA, sehingga dapat memberikan gambaran kepada industri tahu mengenai alternatif pengawetan tahu serta memberikan gambaran mengenai dampak lingkungan kepada penentu kebijakan terkait penggunaan kunyit sebagai bahan pengawet tahu dan penggunaan iradiator sebagai alat untuk mengawetkan tahu. 


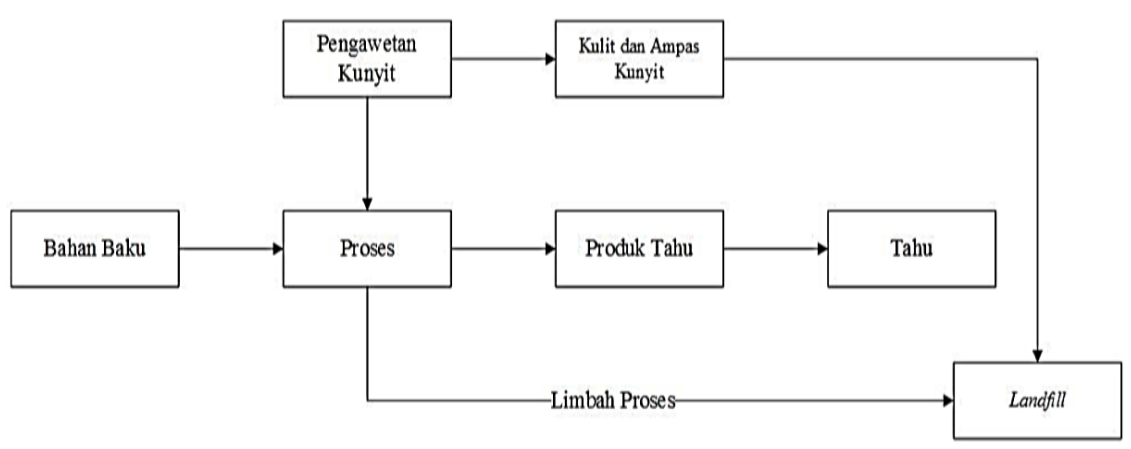

Gambar. 2. Pengawetan Tahu menggunakan Kunyit

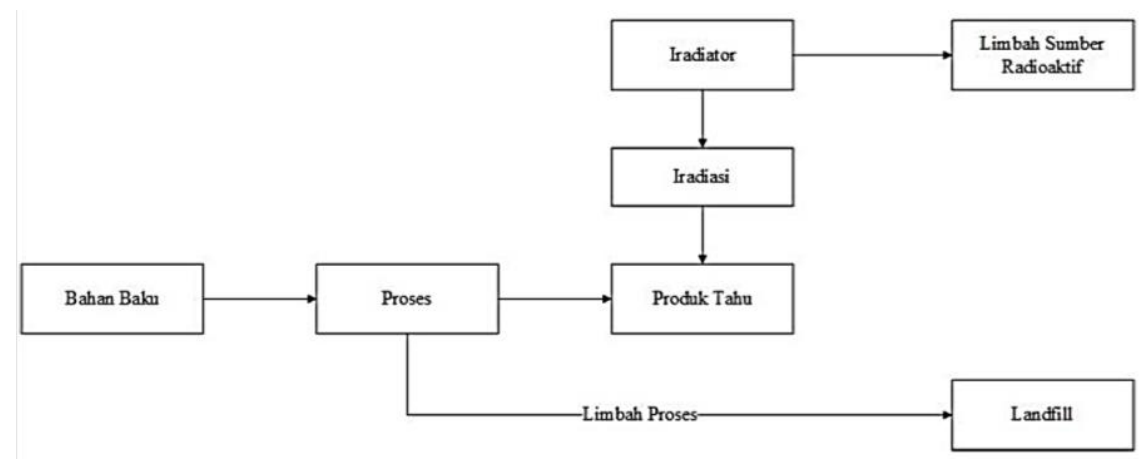

Gambar. 3. Pengawetan Tahu menggunakan Iradiator

Pada penelitian ini, digunakan metode pendekatan cradle to gate, sehingga objek penelitian dimulai dari pengambilan bahan baku tahu sampai dengan produk jadi. Sistem cradle to gate pada produksi tahu yang diawetkan dengan kunyit disajikan pada Gambar 2 dan produksi tahu yang diawetkan menggunakan iradiator disajikan pada Gambar 3.

\section{Inventori Analisis}

Tahap ini merupakan tahap pengumpulan input dan output data pada setiap stasiun kerja yang dianalisis. Data - data yang dikumpulkan pada tahap ini meliputi :

1. Bahan baku dan bahan pembantu, meliputi: jenis dan jumlah.

2. Mesin dan Peralatan, meliputi: jenis, jumlah, dan kapasitas.

3. Proses Produksi, meliputi: urutan proses, jenis dan jumlah bahan bakar, serta limbah yang dihasilkan.

4. Produk, meliputi: jenis dan kapasitas produksi.

Saat membuat inventory assessment (LCI) data yang diperlukan dikumpulkan per jumlah total konsumsi sumber daya, untuk bahan baku data dikumpulkan dalam satuan $\mathrm{kg}$ bahan baku yang dibutuhkan, sedangkan untuk bahan bakar atau energi yang dibutuhkan dalam satuan $\mathrm{kWh}$ atau MJ. Jumlah total emisi mencakup semua emisi yang meninggalkan batas sistem menuju ke udara, air, dan tanah [8] [4].

\section{Penilaian Dampak}

Tahap ini merupakan tahap pengkajian terhadap daur hidup produk tahu. Pengkajian yang dilakukan berupa evaluasi kinerja lingkungan, penilaian dampak lingkungan, dan penilaian risiko [8].

Pada penelitian ini, penilaian analisis dampak menggunakan metode CML (baseline) versi 4.4 dengan database yang digunakan pada adalah Joint Research Center (JRC) Version 3.2 oleh European reference Life Cycle Database dan NERL. CML merupakan metode penilaian dampak yang dikembangkan oleh Institute of Environmental Sciences, Leiden University, Belanda. Penilaian dampak menggunakan metode CML meliputi: analisis climate change, acidification potential, depletion of abiotic resourches, eutrophication, freshwater aquatic ecotoxicity, ozone layer depletion, human toxicity, terrestial 
ecotoxicity, marine aquatic ecotoxicity, dan photochemical oxidation [8].

\section{Interpretasi}

Dalam melakukan tahap interpretasi, untuk menentukan isu-isu penting lingkungan, metode analisis yang dapat dilakukan adalah metode pendekatan analisis kontribusi, yang bertujuan untuk mengidentifikasi data yang memiliki kontribusi terbesar terhadap lingkungan. Selain itu, digunakan juga metode analisis perbaikan hasil, sehingga dapat dirumuskan kesimpulan serta saran perbaikan bagi industri tahu kedepannya [6].

\section{METODE}

Langkah-langkah studi Life Cycle Assessment mengacu pada ISO 14040 tahun 2006, yang dibagi menjadi empat tahap yaitu : (1) tahap pendefinisian tujuan dan ruang lingkup, (2) tahap inventori analisis, (3) tahap penilaian dampak, dan (4) tahap interpretasi. Pengolahan data pada penelitian ini untuk evaluasi dampak lingkungan digunakan software OpenLCA versi 1.6.2. Langkahlangkah penelitian dijabarkan didalam Gambar 4.

Tahapan Pendefinisian Tujuan dan Ruang Lingkup

Pada tahap ini dilakukan studi observasi ke industri tahu yang ada di wilayah Yogyakarta. Observasi dilakukan untuk melihat kondisi lapangan pada industri tahu. Setelah dilakukan observasi, dilakukan pendefinisian tujuan dan ruang lingkup dari penelitian yang akan dilakukan.

\section{Tahapan Inventori Analisis}

Pada tahap ini dilakukan pengambilan data input dan output pada industri tahu di wilayah Kotagede Yogyakarta dan data pengawetan menggunakan iradiator di Pusat Aplikasi Isotop Radiasi (PAIR) BATAN. Data yang akan diambil meliputi kapasitas produksi tahu, jumlah kebutuhan bahan baku utama dan pendukung produksi tahu, konsumsi energi (energi listrik dan bahan bakar) dalam satu kali proses produksi, dan limbah yang dihasilkan.

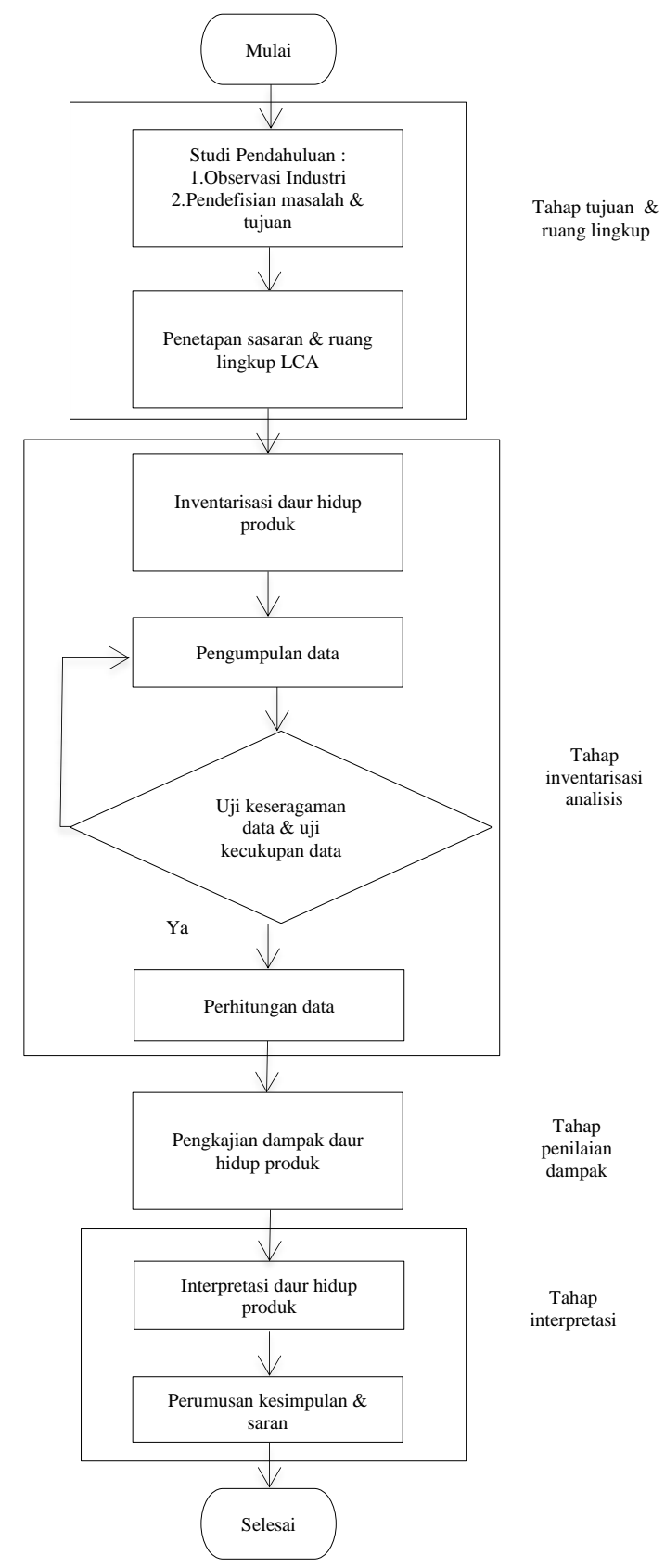

Gambar. 4. Alur Metodologi Penelitian LCA pada Pengawetan Tahu menggunakan Kunyit dan Iradiator

\section{Tahapan Penilaian Dampak}

Tahap ini dilakukan untuk mengkaji dampak yang ditimbulkan terhadap lingkungan dari produksi tahu yang diawetkan menggunakan kunyit maupun iradiator. Penilaian analisis dampak dalam penelitian ini menggunakan metode CML (baseline) versi

Analisis yang dilakukan meliputi: analisis climate change, acidification potential, depletion of abiotic resourches, eutrophication, 
freshwater aquatic ecotoxicity, ozone layer depletion, human toxicity, terrestial ecotoxicity, marine aquatic ecotoxicity, dan photochemical oxidation.

\section{Tahapan Interpretasi}

Pada tahap ini, digunakan metode pendekatan analisis kontribusi, yang bertujuan untuk mengidentifikasi data yang memiliki kontribusi terbesar terhadap lingkungan, dan juga metode analisis perbaikan hasil, yang bertujuan untuk dapat merumuskan kesimpulan serta saran perbaikan bagi industri tahu kedepannya.

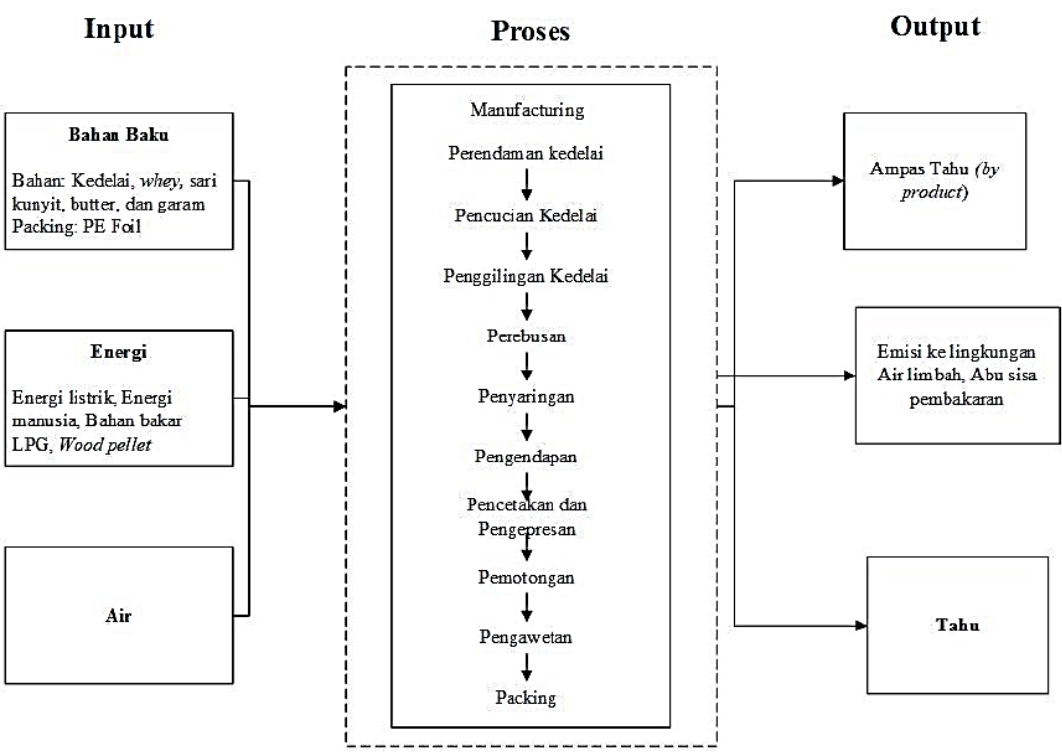

Gambar. 5. Cakupan Studi Life Cycle Assessment Pada Pengawetan Tahu menggunakan Kunyit

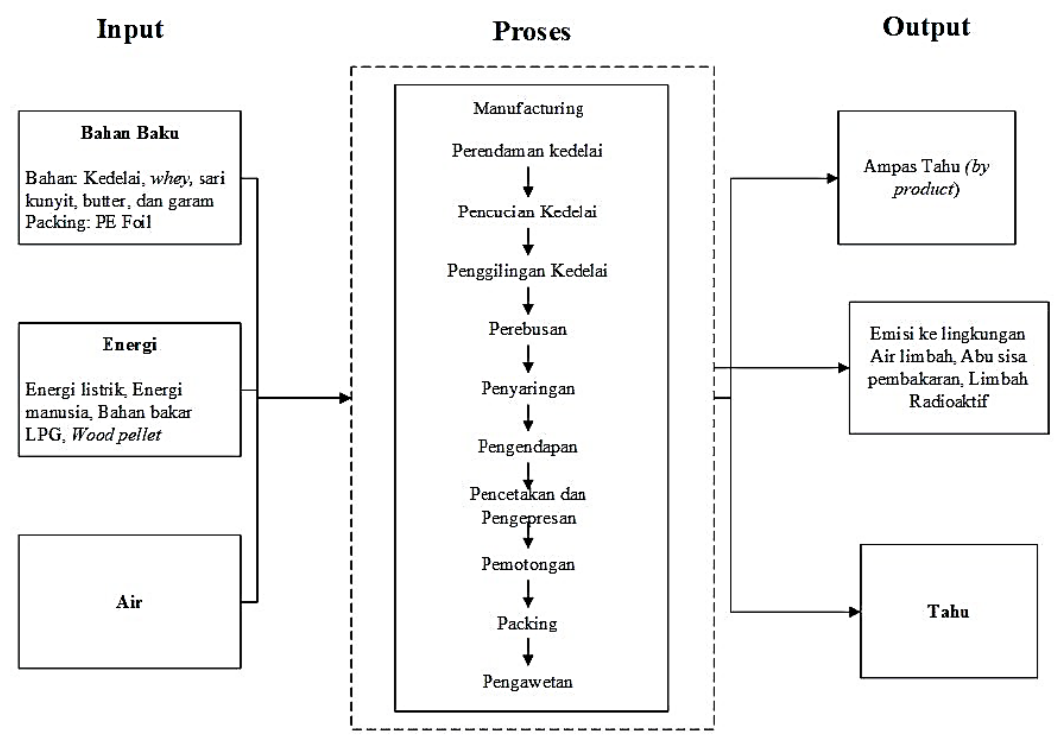

Gambar. 6. Cakupan Studi Life Cycle Assessment Pada Pengawetan Tahu menggunakan Iradiator

\section{HASIL DAN PEMBAHASAN}

\section{Cakupan Studi LCA}

Cakupan studi LCA pada penelitian ini meliputi semua proses yang penting dalam produksi tahu mulai dari proses perendaman biji kedelai, pencucian biji kedelai, penggilingan, perebusan, penyaringan, pengendapan, pencetakan, pemotongan, dan pengawetan. Semua aliran bahan, energi dan emisi untuk tiap-tiap proses dianalisis. Cakupan studi LCA ini ditunjukkan pada Gambar 5 dan Gambar 6.$$
\text { . }
$$ 


\section{Analisis Inventori}

Analisis inventori pada studi ini dilakukan berdasarkan input dan output material di dalam sistem produksi tahu di salah satu pabrik tahu di Kotagede Yogyakarta. Data input pada studi ini terdiri dari: kebutuhan bahan baku, energi/kelistrikan, air, dan bahan pengemas yang digunakan, sedangkan data output berupa produk tahu, by product tahu, dan limbah yang dilepaskan ke lingkungan di setiap prosesnya. Data inventori pengawetan tahu menggunakan kunyit dan iradiator ditampilkan pada Tabel 1.

Tabel. 1. Data Inventori Pengawetan

Tahu menggunakan Kunyit dan Iradiator

\begin{tabular}{|c|c|c|}
\hline Proses Produksi 41,8335 kg Tahu & Kunyit & Iradiator \\
\hline Kedelai & $15 \mathrm{~kg}$ & $15 \mathrm{~kg}$ \\
\hline Butter & $2 \mathrm{oz}$ & $2 \mathrm{oz}$ \\
\hline Garam & $0,2 \mathrm{~kg}$ & $0,2 \mathrm{~kg}$ \\
\hline Sari Kunyit & $1,2 \mathrm{~L}$ & $0 \mathrm{~L}$ \\
\hline PE Foil & $1,44 \mathrm{~kg}$ & $1,44 \mathrm{~kg}$ \\
\hline Kebutuhan Air Pendukung Proses & $1105,8 \mathrm{~L}$ & $70677 \mathrm{~L}$ \\
\hline Kebutuhan Energi Listrik & 1,39 kWh & $1510,58 \mathrm{kWh}$ \\
\hline \multicolumn{3}{|c|}{ Kebutuhan Bahan Bakar Cair : } \\
\hline Liquid Petroleum Gas (LPG) & $3 \mathrm{~kg}$ & $0 \mathrm{~kg}$ \\
\hline \multicolumn{3}{|c|}{ Kebutuhan Bahan Bakar Padat: } \\
\hline Wood Pellet & $0,5 \mathrm{~kg}$ & $0,5 \mathrm{~kg}$ \\
\hline \multicolumn{3}{|l|}{ Emisi ke Permukaan Tanah : } \\
\hline Ampas Tahu & $22,32 \mathrm{~kg}$ & $22,32 \mathrm{~kg}$ \\
\hline \multicolumn{3}{|c|}{ Emisi ke Perairan : } \\
\hline Perendaman & $40 \mathrm{~L}$ & $40 \mathrm{~L}$ \\
\hline BOD5 & $2147,12 \mathrm{mg} / \mathrm{L}$ & $2147,12 \mathrm{mg} / \mathrm{L}$ \\
\hline COD & $3911,68 \mathrm{mg} / \mathrm{L}$ & $3911,68 \mathrm{mg} / \mathrm{L}$ \\
\hline TSS & $453 \mathrm{mg} / \mathrm{L}$ & $453 \mathrm{mg} / \mathrm{L}$ \\
\hline Pencucian & $236,5 \mathrm{~L}$ & $236,5 \mathrm{~L}$ \\
\hline BOD5 & $104,19 \mathrm{mg} / \mathrm{L}$ & $104,19 \mathrm{mg} / \mathrm{L}$ \\
\hline COD & $181,15 \mathrm{mg} / \mathrm{L}$ & $181,15 \mathrm{mg} / \mathrm{L}$ \\
\hline TSS & 219 mg/L & $219 \mathrm{mg} / \mathrm{L}$ \\
\hline $\begin{array}{c}\text { Pengendapan, Pencetakan \& } \\
\text { Pengepresan }\end{array}$ & $295,85 \mathrm{~L}$ & $295,85 \mathrm{~L}$ \\
\hline BOD5 & $4053,59 \mathrm{mg} / \mathrm{L}$ & $4053,59 \mathrm{mg} / \mathrm{L}$ \\
\hline COD & $7411,95 \mathrm{mg} / \mathrm{L}$ & $7411,95 \mathrm{mg} / \mathrm{L}$ \\
\hline TSS & $758 \mathrm{mg} / \mathrm{L}$ & $758 \mathrm{mg} / \mathrm{L}$ \\
\hline Pengawetan & $450 \mathrm{~L}$ & $450 \mathrm{~L}$ \\
\hline BOD5 & $4068,87 \mathrm{mg} / \mathrm{L}$ & $0 \mathrm{mg} / \mathrm{L}$ \\
\hline COD & $7438,88 \mathrm{mg} / \mathrm{L}$ & $0 \mathrm{mg} / \mathrm{L}$ \\
\hline TSS & $2724 \mathrm{mg} / \mathrm{L}$ & $0 \mathrm{mg} / \mathrm{L}$ \\
\hline
\end{tabular}

\section{Penilaian Dampak/Impact Assessment}

Penilaian dampak digunakan untuk menganalisis dampak suatu proses terhadap lingkungan dan kesehatan manusia. Pada penelitian ini, telah dilakukan penilaian dampak terhadap sebelas kategori dampak dengan menggunakan metode CML (Baseline) versi 4.4 dengan bantuan software OpenLCA untuk membantu perhitungan. Pada Tabel 2 ditampilkan hasil analisis dampak pengawetan tahu menggunakan kunyit dan iradiator.

Pengawetan tahu menggunakan kunyit maupun iradiator menimbulkan beberapa dampak yang berpengaruh terhadap lingkungan dan kesehatan manusia, seperti yang terlihat pada Tabel 1 dampak yang ditimbulkan berupa acidification, climate change, eutrophication, freshwater aquatic ecotoxicity, human toxicity, marine aquatic ecotoxicity, photochemical oxidation, dan terrestrial ecotoxicity.

Tabel. 2. Hasil Analisis Dampak Pengawetan Tahu dengan Kunyit dan Iradiator

\begin{tabular}{|c|c|c|c|}
\hline Kategori Dampak & \multicolumn{2}{|c|}{ Kunyit Iradiator } & Satuan \\
\hline Acidification potential & 0,0062 & 0,0054 & $\mathrm{~kg} \mathrm{SO}_{2}$ eq. \\
\hline Climate change - GWP100 & 16,6714 & 14,5133 & $\mathrm{~kg} \mathrm{CO} 2$ eq. \\
\hline $\begin{array}{c}\text { Depletion of abiotic resources - } \\
\text { elements, ultimate reserves }\end{array}$ & 0,0000 & 0,0000 & $\begin{array}{c}\text { kg antimon } \\
\text { eq. }\end{array}$ \\
\hline $\begin{array}{c}\text { Depletion of abiotic resources - } \\
\text { fossil fuels }\end{array}$ & 0,0000 & 0,0000 & MJ \\
\hline Eutrophication & 0,0179 & 0,0156 & kg PO4--- eq. \\
\hline Freshwater aquatic ecotoxicity & 1,0054 & 0,8753 & $\begin{array}{c}\text { kg 1,4- } \\
\text { diklorobenzen } \\
\text { eq. }\end{array}$ \\
\hline Human toxicity & 0,0118 & 0,0103 & $\begin{array}{c}\text { kg 1,4- } \\
\text { diklorobenzen } \\
\text { eq. }\end{array}$ \\
\hline Marine aquatic ecotoxicity & 0,1091 & 0,0950 & $\begin{array}{c}\text { kg 1,4- } \\
\text { diklorobenzen } \\
\text { eq. }\end{array}$ \\
\hline Ozone layer depletion & 0,0000 & 0,0000 & kg CFC-11 eq. \\
\hline Photochemical oxidation & 0,0001 & 0,0001 & kg etilen eq. \\
\hline Terrestrial ecotoxicity & 0,0002 & 0,0001 & $\begin{array}{c}\text { kg 1,4- } \\
\text { iklorobenzen } \\
\text { eq. }\end{array}$ \\
\hline
\end{tabular}

Asidifikasi terjadi akibat adanyacemaran polutan yang menyebabkan pengasaman. Pada proses produksi tahu yang diawetkan menggunakan kunyit maupun iradiator diemisikan polutan berupa ammonia $\left(\mathrm{NH}_{3}\right)$, sulfur dioksida $\left(\mathrm{SO}_{2}\right)$ dan nitrogen oksida $\left(\mathrm{NO}_{\mathrm{x}}\right)$ yang berasal dari residu kedelai dan pembakaran wood pellet. Polutan ini akan terkonversi dan berinteraksi dengan molekul air yang ada di awan, sehingga polutan ini akan berubah menjadi $\mathrm{H}_{2} \mathrm{SO}_{4}$ dan $\mathrm{HNO}_{3}$ yang menyebabkan air hujan yang jatuh ke bumi bersifat asam (hujan asam). Efek ini menyebabkan terganggunya siklus nutrien yang berdampak pada hilangnya tumbuhan air dan mikroorganisme, sehingga siklus tropik rantai makanan akan berubah, perubahan siklus tropik rantai makanan ini dapat menyebabkan 
punahnya populasi hewan maupun tumbuhan yang berada di dalam perairan tersebut [9].

Dampak yang kedua yaitu climate change $\left(\mathrm{GWP}_{100}\right)$, dampak ini merupakan dampak yang paling besar berkontribusi pada pengawetan tahu menggunakan kunyit maupun iradiator yang ditimbulkan oleh emisi dinitrogen monoksida dari residu kedelai. Dampak ini dikenal juga dengan efek rumah kaca, yang menyebabkan meningkatnya suhu di permukaan bumi.

Emisi dinitrogen monoksida dari residu kedelai juga mengakibatkan terjadinya eutrofikasi. Dampak ini menyebabkan pergeseran komposisi spesies yang tidak diinginkan dan meningkatkan produksi biomassa pada ekosistem perairan maupun terestrial. Eutrofikasi perairan menyebabkan alga tumbuh sangat cepat, alga ini menghambat sinar matahari masuk kedalam air, sehingga menyebabkan penurunan fotosintesis dan berkurangnya produksi oksigen [8]. Emisi limbah cair yang dihasilkan pada proses produksi juga menjadi salah satu penyebab eutrofikasi. Berdasarkan hasil analisis limbah, nilai BOD, COD, dan TSS limbah sangat tinggi dan melebihi baku mutu air limbah untuk industri tahu di wilayah Yogyakarta.

Gas karbon monoksida yang diemisikan dari pembakaran yang tidak sempurna menyebabkan terjadinya photochemical oxidation. Gas ini menyumbangkan $0,0001 \mathrm{~kg}$ etilen eq pada pengawetan tahu menggunakan kunyit dan 0,00009 $\mathrm{kg}$ etilen eq pada pengawetan tahu menggunakan iradiasi terhadap dampak photochemical oxidation. Emisi Chlorpyrifos, trifluralin, glyphosate, dan metolachlor menyebabkan terjadinya freshwater and marine aquatic ecotoxicity. Emisi ini diakibatkan oleh residu kedelai. Emisi ini menyebabkan perubahan pada ekosistem air tawar maupun air laut, sehingga dapat menyebabkan punahnya sekumpulan populasi yang berada di dalamnya dan mengakibatkan ekosistem terganggu dan merubah tingkatan tropi rantai makanan.

Pengawetan tahu menggunakan kunyit juga menyumbangkan kontribusi terhadap human toxicity sebesar $0,01179 \mathrm{~kg} \mathrm{1,4-}$ diklorobenzen eq dan $0,0102 \quad \mathrm{~kg} \quad 1,4-$ diklorobenzen eq pada pengawetan tahu menggunakan iradiator. Dampak inidisebabkan karena adanya emisi nitrogen oksida ke udara dan trifluralin ke air. Dampak yang terakhir ditimbulkan berupa terrestial ecotoxicity yang disebabkan oleh emisi glyphosate dan 2,4-D ke udara. Dampak ini memberikan efek terhadap ekosistem terestrial.

Namun demikian, pada pengawetan tahu menggunakan kunyit maupun iradiator tidak menimbulkan dampak terhadap depletion of abiotic resources (termasuk energi fossil) dan ozone layer depletion, tetapi pengawetan tahu menggunakan iradiator menghasilkan limbah radioaktif dengan aktivitas $0,11 \mathrm{kCi}$. Menurut PP No 27 Tahun 2002, limbah ini dikategorikan sebagai limbah radioaktif tingkat sedang.

\section{Interpretasi}

Gambar 7 menampilkan hasil komparasi penilaian dampak lingkungan, dilakukan komparasi terhadap pengawetan tahu menggunakan kunyit maupun iradiator.Berdasarkan Gambar 7, dampak lingkungan yang paling dominan ditimbulkan adalah climate change dengan metode pengawetan tahu yang memberikan kontribusi terbesar terhadap dampak lingkungan yaitu pengawetan tahu menggunakan kunyit. Pada proses pengawetan, pembakaran wood pellet dan residu kedelai menyebabkan emisi ke udara dan air yang sangat besar daripada penggunaan bahan lainnya. Emisi yang paling dominan dilepaskan ke lingkungan yaitu $\mathrm{NO}_{\mathrm{x}}, \mathrm{SO}_{2}$, dan $\mathrm{NH}_{3}$ serta emisi chlorpyrifos, trifluralin, glyphosate, dan metolachlor ke air yang mengkontaminasi air, sehingga menyebabkan terjadinya freshwater aquatic ecotoxicity.

Emisi ini dapat diminimalisir dengan menekan penggunaan bahan bakar, sehingga emisi gas $\mathrm{NO}_{\mathrm{x}}, \mathrm{SO}_{2}$, dan $\mathrm{CO}$ berkurang. Limbah cair dari proses produksi tahu berupa limbah cair proses pencucian, perendaman, air kecutan (whey), dan air rebusan (whey + air kunyit) juga menyumbangkan dampak terhadap eutrofikasi perairan, sehingga limbah ini perlu dilakukan pengolahan terlebih dahulu sebelum dilimbahkan ke lingkungan. 


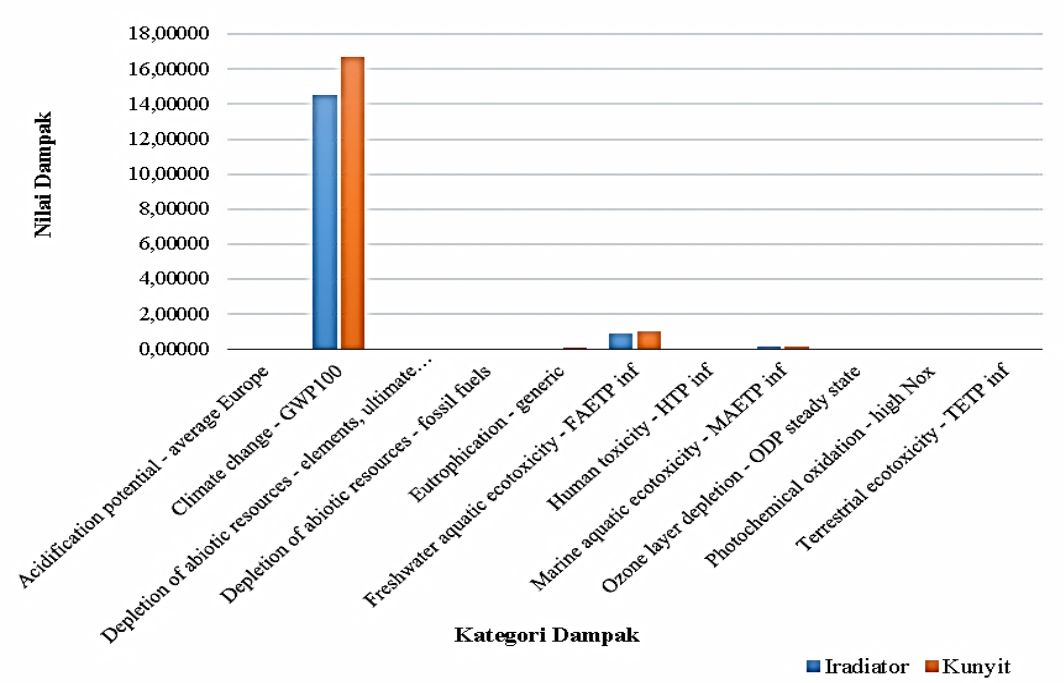

Gambar. 7. Hasil Komparasi Kategori Dampak Pengawetan Tahu

\section{KESIMPULAN}

Dampak lingkungan yang disebabkan dari pengawetan tahu menggunakan kunyit maupun iradiator berupa acidification potential, climate change, eutrophication, freshwater aquatic ecotoxicity, human toxicity, marine aquatic ecotoxicity, photochemical oxidation, dan terrestial ecotoxicity. Kontribusi dampak terhadap lingkungan yang paling dominan terjadi pada pengawetan tahu menggunakan kunyit dan iradiator adalah climate change, dengan kontribusi sebesar 16,6714 dan $14,5133 \mathrm{~kg} \mathrm{CO}_{2}$ eq.

Berdasarkan studi komparasi dan analisis kontribusi, pengawetan tahu menggunakan iradiator lebih ramah lingkungan, sehingga teknologi pengawetan ini dapat dijadikan teknologi alternatif pada pengawetan makanan.

\section{SARAN}

Berdasarkan penelitian yang telah dilakukan terhadap pengawetan tahu menggunakan kunyit dan iradiator dengan pendekatan LCA, penelitian mengenai LCA ini perlu dikembangkan pada produk - produk lainnya dan disempurnakan lagi agar hasil analisis yang diperoleh lebih baik lagi.

\section{DAFTAR PUSTAKA}

1. Mostafavi, H. A., Mirmajlessi, S. M. dan Fathollahi, H., 2012. The Potential of Food Irradiation: Benefits and Limitations.
2. Liberty, J., Dickson, D., Achebe, A. dan Salihu, M., 2013. An Overview of the Principles and Effects of Irradiation on Food Processing and Preservation. International Journal of Multidisciplinary and Current Research.

3. Pusat Diseminasi dan Kemitraan., 2010. Aplikasi Teknik Nuklir Dalam Pengawetan Bahan Pangan.

4. ISO 14040. 2006. Environmental Management-Life Cycle AssessmentPrinciples and Framework. ISO Press.

5. Suryadarmawan, V. A., Djunaidi, M. dan Nursanti, I., 2014. Analisis Cradle To Grave Produk Batik Cabut. Skripsi Universitas Muhammadiyah Surakarta.

6. Harjanto, T. R., Fahrurrozi, M. dan Bendiyasa, I. M., 2012. Life Cycle Assessment Pabrik Semen PT Holcim Indonesia Tbk. Pabrik Cilacap: Komparasi antara Bahan Bakar Batubara dengan Biomassa. Jurnal Rekayasa Proses, Vol.6 (2).

7. CURRAN, M., 1996, "Environmental LifeCycle Assessment", McGraw-Hill, New York.

8. $\mathrm{GaBi}, 2010$. Handbook for Life Cycle Assessment (LCA) Using The GaBi Software. s.l.:PE International, Leinfelden - Echterdingen Germany.

9. Effendi, H., 2003. Telaah Kualitas Air. Yogyakarta: Kanisius.

10. Negara, K. S., 2002. Peraturan Pemerintah No 27 Tahun 2002 Tentang Pengelolaan Limbah Radioaktif, Indonesia: Kementerian Sekretariat Negara. 